\title{
Comparative study between sprayed and inhaled nebulized lidocaine for suppression of hemodynamic response to laryngoscopy and oral endotracheal intubation
}

\author{
By \\ Ahmed Abdulmaged Ahmed ${ }^{* 1}$; Dr. Hasan Sarhan Haider ${ }^{* 2}$ \\ ${ }^{* 1}$ M.B.Ch.B/ Fallujah Teaching Hospital; ${ }^{* 2}$ M.B.Ch.B/DA/F.I.C.M.S A\&IC \\ Consultant anesthetist
}

\begin{abstract}
Background: Direct laryngoscopic manipulation and endotracheal intubation are noxious stimuli capable of producing hemodynamic changes characterized by tachycardia, hypertension, and arrhythmias. Which are tolerated in normotensive healthy individuals but had greater impact in patients with cardiovascular and cerebrovascular diseases lead to increased morbidity and mortality. Aim of the study: To compare the efficacy of sprayed and inhaled nebulized lidocaine in suppressing the cardiovascular response to laryngoscopy and tracheal intubation in normotensive patients undergoing general anesthesia. Patient and method: 80 adult patients undergoing elective surgery under general anesthesia with endotracheal intubation were randomly allocated into two equal groups. Patients in nebulized lidocaine (NL) group received pre-induction nebulized ( $1 \mathrm{ml}$ of $10 \%$ ) lidocaine, while those in sprayed lidocaine (SL) group received pre-induction sprayed (10 puffs of 10\%) lidocaine. The general anesthesia technique was standardized for the two groups. The primary outcome measures were hemodynamic response at 1, 3, 6, 9, and 12 min after intubation. The secondary outcome measures were to note down any adverse effects associated with drugs. The statistical package used was SPSS version 25.Results: There was a statistically significant difference $(P<0.05)$ between nebulizes and sprayed lidocaine in heart rate, systolic, diastolic and mean arterial pressures at different time points after tracheal intubation with nebulized lidocaine being most effective and better toleration.Conclusion: The hemodynamic instability was lesser with nebulized lidocaine as compared to sprayed lidocaine. The effect was on heart rate and blood pressure. Use of nebulized lidocaine is simple, safe, effective and better patient acceptance.
\end{abstract}

Keywords: Laryngoscopy, endotracheal intubation; Cardiovascular response; Lidocaine, sprayed, nebulization. 


\section{Introduction}

The major responsibility of any anesthesiologist is the management of the airway to provide adequate ventilation to the patient by securing airway during general anesthesia. As such, no anesthesia is safe unless diligent efforts are devoted to maintain an intact functional airway.Endotracheal intubation is the overall accepted, "Gold standard of securing the airway and providing adequate ventilation." However, endotracheal intubation requires time, a skilled anesthesiologist, appropriate instruments, and adequate circumstances with respect to space and illumination.

Direct laryngoscopy and endotracheal intubation following induction of anesthesia is almost always associated with hemodynamic changes due to reflex sympathetic discharge caused by epipharyngeal and laryngopharyngeal stimulation ${ }^{[1]}$. This increased sympatho-adrenal activity may result in hypertension, tachycardia, and arrhythmias ${ }^{[2,3,4]}$. This increase in blood pressure and heart rate are usually transitory, variable, and unpredictable. Transitory hypertension and tachycardia are probably of no consequence in healthy individuals ${ }^{[5]}$ but either or both may be hazardous to patients with hypertension, myocardial insufficiency, penetrating eye injuries, intracranial lesion, or cerebrovascular diseases. This laryngoscopic reaction in such individuals may predispose to development of pulmonary oedema ${ }^{[6]}$ myocardial insufficiency ${ }^{[7]}$ and cerebrovascular accident ${ }^{[8]}$. At least in such individuals there is a necessity to blunt these harmful laryngoscopic reactions. Attenuation of presser responses to manipulation of the airway has been practiced either by deepening the plane of anesthesia ${ }^{[9}$, ${ }^{10]}$, by the use of drugs known to obtund them or by using advanced airway devices ${ }^{[11,12]}$.

Many methods have been devised to reduce the extent of hemodynamic events including high dose of opioids ${ }^{[5,13]}$, alpha and beta adrenergic 
blockers ${ }^{[14,15]}$, calcium channel antagonist like diltiazem, verapamil ${ }^{[16]}$ and vasodilatation drugs like nitroglycerine ${ }^{[17]} . \alpha 2$ - agonist like Clonidine ${ }^{[18]}$ and Dexmedetomidine ${ }^{[19]}$ are used.Various studies have reviewed the effect of Lidocaine in forms like viscous Lidocaine ${ }^{[20]}$, aerosols ${ }^{[21]}$, oropharyngeal sprays ${ }^{[22]}$, and intravenous route ${ }^{[23,24]}$ to blunt these responses.Topical anesthesia with lidocaine applied to the larynx and trachea in a variety of ways remains a popular method used alone or in combination with others.

\section{Patient and method}

It is a prospective comparative randomized, non-blinded clinical trial after obtaining the approval of the Iraqi Scientific Council of Anesthesia and Intensive Care. It was undertaken in Baghdad Teaching Hospital and Ghazi Al-Hariri Surgical Specialties Hospital from 14th of December 2019 to 1st of April 2020. Inclusion criteria: (Patients aged 18-50 years; Weighting 50$80 \mathrm{~kg}$ of either sex; ASA1; Basal heart rate (65-75) beats per minute;Elective surgery under general anesthesia with oral endotracheal intubation) as well as the Exclusion criteria: ( Refusal to consent;Allergy to any drug used in the study; Inability to communicate; Suspected difficult intubation;Thoracic, head and neck surgery; Patient with significant gastroesophageal reflex).

The 80 participants were randomly allocated into two equal groups. Random allocation was achieved by means of sealed envelopes marked as group NL or group SL. Patients in group NL received nebulized lidocaine, while those in group SL received sprayed lidocaine.

Preanesthetic assessment including full history, proper examination, and revision of routine investigations were done. Basal reading of systolic blood pressure, diastolic blood pressure, mean arterial pressure, heart rate, and weight were recorded. Then the patients transferred to operating room where monitor was attached and intravenous 20G cannula was inserted and fixed. 
Patients in group NL (Nebulized Lidocaine) were nebulized with 10\% lidocaine $1 \mathrm{ml}(100 \mathrm{mg})$ in sitting position by standard nebulizer with a fit face mask attached to Auxiliary oxygen flowmeters of anesthetic machine with $\mathrm{O} 2$ flow at $3 \mathrm{~L} / \mathrm{min}$., then the patient was asked to inhale vapor of the local anesthetic deeply for about 2 minutes until the dose is complete. Patients in group SL (sprayed lidocaine) were sprayed with $10 \%$ lidocaine 10 puffs by metered dose lidocaine pump spray (each puff equal $0.1 \mathrm{ml}$ that equal $10 \mathrm{mg}$ ) in sitting position. Lidocaine spray was applied as single puff bilaterally to palatopharyngeal and palatoglossal arches, soft palate, posterior oropharyngeal wall, and base of tongue, as well as 2 puffs to the epiglottic vallecular region. During and after administration of drug by different techniques any complications such as coughing, gagging, sore throat, and hoarseness was documented and patient satisfaction assessed. After the patients in each group received lidocaine in different techniques, the patient lied back on the operating table, monitor device was reconnected, and standard monitoring was started. Intravenous fluid started and pre-induction with IV 1-2 mg of midazolam, $10 \mathrm{mg}$ of metoclopramide and $50 \mathrm{mg}$ of ranitidine were administered slowly. Induction was given after oxygenation with fentanyl $1 \mathrm{mcg} / \mathrm{kg}$, propofol $1.5-2.5 \mathrm{mg} / \mathrm{kg}$ (until the loss of verbal response) followed by rocuronium $0.6 \mathrm{mg} / \mathrm{kg}$ and $8 \mathrm{mg}$ of dexamethasone. Oxygenation was maintained by manual IPPV. After 2 minutes oral intubation was done by using Macintosh laryngoscope and appropriate size single-lumen cuffed endotracheal tube that was secured after confirmation of proper position. Intubation was done by well-trained anesthetist from first attempt that not exceed $15 \mathrm{sec}$. Then the patient connected to anesthetic machine and anesthesia was maintained with $2 \%$ of sevoflurane. Post intubation reading of parameters at 1, 3, 6, 9, and 12 minutes before starting of surgical stimulation were noted. After obtaining all reading sevoflurane switched to isoflurane and a bolus analgesic dose of ketamine $(0.5 \mathrm{mg} / \mathrm{kg})$ 
and paracetamol infusion $(10 \mathrm{mg} / \mathrm{kg})$ were administered with continuous standard monitoring and incremental doses of muscle relaxant as needed. At the end of the surgery, muscle relaxation was reversed with IV neostigmine $0.04 \mathrm{mg} / \mathrm{kg}$ and IV atropine $0.015 \mathrm{mg} / \mathrm{kg}$ and trachea was extubated. Patients were observed for few minutes in the operating room and then transferred to post anesthesia care unit where they were observed till patient met the recovery room discharge criteria.

Statistical Analysis: using the Statistical Package for Social Sciences (SPSS) version 25 and Microsoft excel 2016 to generate graphics. Fisher Exact test has been used to find the significance regarding gender and Chisquared test for incidence of coughing and gagging. Independent t-test (two tailed) was used to compare the continuous variables among study groups accordingly. A level of $\mathrm{P}$ - value less than 0.05 was considered significant.

\section{Result}

The demographic data such age, weight and male: female ratio was compared in both groups and there was no significant difference. The basal reading of parameters (heart rate, systolic blood pressure, diastolic blood pressure, and mean arterial pressure) was similar in the two groups.

Table (1): the baseline characteristics of study groups

\begin{tabular}{|c|c|c|c|}
\hline Parameters & NL & SL & p-value \\
\hline Age(years) & $29.43 \pm 6.18$ & $31.26 \pm 7.35$ & 0.2317 \\
\hline Weight(kg) & $65.47 \pm 6.21$ & $67.38 \pm 5.33$ & 0.1439 \\
\hline Gender (M:F Ratio) & $17: 23$ & $13: 27$ & 0.3684 \\
\hline Basal HR(bpm) & $71.06 \pm 3.01$ & $69.92 \pm 3.40$ & 0.1164 \\
\hline Basal SBP(mmHg) & $120.42 \pm 11.55$ & $122.21 \pm .10 .12$ & 0.4632 \\
\hline
\end{tabular}




\begin{tabular}{|c|c|c|c|}
\hline Basal DBP(mmHg) & $73.96 \pm 9.45$ & $74.86 \pm 8.75$ & 0.6597 \\
\hline Basal MAP(mmHg) & $89.44 \pm 10.51$ & $90.64 \pm 9.20$ & 0.5812 \\
\hline
\end{tabular}

Mean age of subjects for NL (nebulized lidocaine) group was (29.43 \pm 6.18 ) years and for SL (sprayed lidocaine) group was (31.26 \pm 7.35$)$ years with no significance $(\mathrm{P}-$ Value $=0.2317)$.

Mean weight of subjects for nebulized lidocaine (NL) group was $(65.47 \pm 6.21) \mathrm{Kgs}$ and for (SL) group was $(67.38 \pm 5.33) \mathrm{kg}$ with no significance $(\mathrm{P}-$ Value $=0.1439)$.

Mean basal heart rate for nebulized lidocaine (NL) group was $(71.06 \pm 3.01) \mathrm{bpm}$ and for (SL) group was $(69.92 \pm 3.40) \mathrm{bpm}$ with no significance $(\mathrm{P}-$ Value $=0.1164)$. Mean systolic blood pressure $(\mathrm{SBP})$ of subjects for nebulized lidocaine (NL) group was $(120.42 \pm 11.55) \mathrm{mmHg}$ and for (SL) group was $(122.21 \pm .10 .12) \mathrm{mmHg}$ with no significance (PValue $=0.4632$ ).

Mean diastolic blood pressure (DBP) of subjects for nebulized lidocaine (NL) group was $(73.96 \pm 9.45) \mathrm{mmHg}$ and for (SL) group was (74.86 \pm 8.75$)$ $\mathrm{mmHg}$ with no significance $(\mathrm{P}-\mathrm{Value}=0.6597)$. Mean arterial blood pressure (MAP) of subjects for nebulized lidocaine (NL) group was $(89.44 \pm 10.51)$ $\mathrm{mmHg}$ and for (SL) group was $(90.64 \pm 9.20) \mathrm{mmHg}$ with no significance (PValue $=0.5812$ ). Thus, it is evident that study groups were similar in nature.

Table (2): Showing complications

\begin{tabular}{|c|c|c|c|c|l|}
\hline \multirow{2}{*}{ Complications } & \multicolumn{2}{|c|}{ NL group } & \multicolumn{2}{|c|}{ SL group } & \multirow{2}{*}{ P-value } \\
\cline { 2 - 5 } & $\mathrm{N}$ & $\%$ & $\mathrm{~N}$ & $\%$ & \\
\hline $\begin{array}{c}\text { Coughing or } \\
\text { Gagging }\end{array}$ & 4 & 10 & 18 & 45 & 0.0005 \\
\hline
\end{tabular}




\begin{tabular}{|c|c|c|c|c|c|}
\hline Bitter taste & 40 & 100 & 40 & 100 & 1 \\
\hline Sore throat & 2 & 5 & 4 & 10 & 0.3989 \\
\hline Horsness & 2 & 5 & 5 & 12.5 & 0.2382 \\
\hline
\end{tabular}

Table (3): Patient Satisfaction Score

\begin{tabular}{|c|c|c|c|c|}
\hline \multirow{2}{*}{ Patient Satisfaction Score } & \multicolumn{2}{|c|}{ NL group } & \multicolumn{2}{c|}{ SL group } \\
\cline { 2 - 5 } & $\mathrm{N}$ & $\%$ & $\mathrm{~N}$ & $\%$ \\
\hline Very dissatisfied (1) & 0 & 0 & 10 & 25 \\
\hline Dissatisfied (2) & 2 & 5 & 5 & 12.5 \\
\hline Unsure (3) & 5 & 12.5 & 15 & 37.5 \\
\hline Satisfied (4) & 11 & 27.5 & 8 & 20 \\
\hline Very satisfied (5) & 22 & 55 & 2 & 5 \\
\hline Mean \pm SD & $4.325 \pm 0.88$ & $2.675 \pm 1.20$ \\
\hline P-value & & \multicolumn{5}{c}{} \\
\hline
\end{tabular}

Table (4): changes in mean heart rate

\begin{tabular}{|c|c|c|c|c|c|c|c|}
\hline \multicolumn{2}{|c|}{ Heart Rate } & Group & $\mathrm{N}$ & Mean & SD & $\begin{array}{l}\text { Std. } \\
\text { Error }\end{array}$ & P-Value \\
\hline \multirow{2}{*}{\multicolumn{2}{|c|}{ Basal }} & NL & 40 & 71.06 & 3.01 & 0.47 & \multirow{2}{*}{0.1164} \\
\hline & & SL & 40 & 69.92 & 3.40 & 0.53 & \\
\hline \multirow{5}{*}{ 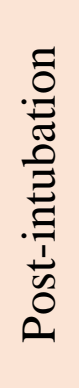 } & \multirow{2}{*}{$1 \mathrm{~min}$} & NL & 40 & 74.96 & 5.95 & 0.94 & \multirow{2}{*}{0.0275} \\
\hline & & SL & 40 & 78.02 & 6.23 & 0.98 & \\
\hline & \multirow{2}{*}{$3 \min$} & NL & 40 & 75.31 & 5.56 & 0.87 & \multirow{2}{*}{0.0100} \\
\hline & & SL & 40 & 78.87 & 6.46 & 1.02 & \\
\hline & $6 \mathrm{~min}$ & NL & 40 & 75.15 & 6.98 & 1.10 & 0.0152 \\
\hline
\end{tabular}




\begin{tabular}{|l|c|c|c|c|c|c|c|}
\hline & SL & 40 & 78.96 & 6.74 & 1.06 & \\
\cline { 2 - 7 } & \multirow{3}{*}{$9 \mathrm{~min}$} & $\mathrm{NL}$ & 40 & 74.43 & 6.12 & 0.96 & \multirow{2}{*}{0.1210} \\
\cline { 2 - 7 } & SL & 40 & 76.78 & 7.24 & 1.14 & \\
\cline { 2 - 7 } & \multirow{2}{*}{$12 \mathrm{~min}$} & $\mathrm{NL}$ & 40 & 73.27 & 5.75 & 0.90 & \multirow{2}{*}{0.4764} \\
\cline { 2 - 7 } & SL & 40 & 74.23 & 6.24 & 0.98 & \\
\hline
\end{tabular}

In group NL (nebulized lidocaine), the basal HR was (71.06 \pm 3.01$) \mathrm{bpm}$, 1 minute after intubation, it was $(74.96 \pm 5.95) \mathrm{bpm}$. Subsequently, the elevated heart rate started settling down 6 minutes $(75.15 \pm 6.98) \mathrm{bpm}$. By 3 , 9 , and 12 minutes it was $(75.3 \pm 5.56),(74.43 \pm 6.12)$, and $(73.27 \pm 5.75) \mathrm{bpm}$ respectively.

In group SL (sprayed lidocaine), the basal HR was (69.92..3.40) bpm, 1 minute after intubation, it was $(78.02 \pm 6.23) \mathrm{bpm}$. Subsequently, the elevated heart rate started settling down 9 minutes $(76.78 \pm 7.42) \mathrm{bpm}$. By 3, 6, and 12 minutes it was $(78.87 \pm 6.46),(78.96 \pm 6.74)$, and $(74.23 \pm 6.24)$ bpm respectively. There was significant difference in the heart rate between the two groups at $1^{\text {st }}, 3$ rd, and $6^{\text {th }}$ minute post-intubation ( $\mathrm{P}-$ Value $<0.05$ ).

Table (5): changes in mean systolic blood pressure

\begin{tabular}{|c|c|c|c|c|c|c|c|}
\hline \multicolumn{2}{|c|}{ SBP } & Group & $\mathrm{N}$ & Mean & SD & $\begin{array}{c}\text { Std. } \\
\text { Error }\end{array}$ & P-Value \\
\hline \multirow{2}{*}{\multicolumn{2}{|c|}{ Basal }} & NL & 40 & 120.42 & 11.55 & 1.82 & \multirow{2}{*}{0.4632} \\
\hline & & SL & 40 & 122.21 & 10.12 & 1.60 & \\
\hline \multirow{7}{*}{ 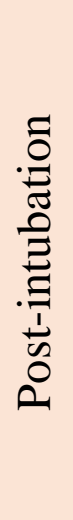 } & \multirow{2}{*}{$1 \mathrm{~min}$} & NL & 40 & 125.13 & 13.24 & 2.09 & \multirow{2}{*}{0.0163} \\
\hline & & SL & 40 & 132.86 & 14.87 & 2.35 & \\
\hline & \multirow{2}{*}{$3 \min$} & NL & 40 & 126.41 & 13.66 & 2.15 & \multirow{2}{*}{0.0259} \\
\hline & & $\mathrm{SL}$ & 40 & 133.74 & 15.16 & 2.39 & \\
\hline & \multirow{2}{*}{$6 \min$} & NL & 40 & 124.61 & 12.87 & 2.03 & \multirow{2}{*}{0.0653} \\
\hline & & SL & 40 & 130.22 & 13.95 & 2.20 & \\
\hline & $9 \min$ & NL & 40 & 121.94 & 11.54 & 1.82 & 0.1965 \\
\hline
\end{tabular}




\begin{tabular}{|l|l|c|c|c|c|c|c|}
\hline & & SL & 40 & 125.42 & 12.34 & 1.95 & \\
\cline { 2 - 7 } & \multirow{2}{*}{$12 \mathrm{~min}$} & NL & 40 & 118.86 & 11.02 & 1.74 & \multirow{2}{*}{0.169} \\
\cline { 3 - 7 } & SL & 40 & 122.35 & 11.46 & 1.81 & \\
\hline
\end{tabular}

In group NL (nebulized lidocaine) the basal value of SBP was $(120.42 \pm 11.55) \mathrm{mmHg}, 1$ minute following intubation, the SBP increased to (125.13 \pm 13.24$) \mathrm{mmHg}$. This elevated pressure started coming down by 6 minutes $(124.61 \pm 12.87) \mathrm{mmHg}$. By 3, 9 and 12 minutes it was (126.41 \pm 13.66$),(121.94 \pm 10.54)$, and $(118.86 \pm 11.02) \mathrm{mmHg}$ respectively.

In group SL (sprayed lidocaine) the basal value of SBP was $(122.21 \pm 10.12) \mathrm{mmHg}, 1$ minute following intubation, the SBP increased to (132.86 \pm 14.87$) \mathrm{mmHg}$. This elevated pressure started coming down by 6 minutes $(130.22 \pm 13.95) \mathrm{mmHg}$. By 3, 9 and 12 minutes it was (133.74 \pm 15.16$),(125.42 \pm 12.34)$, and $(122.35 \pm 11.46) \mathrm{mmHg}$ respectively. There was statistical significance between two groups in the 1 st, and $3^{\text {rd }}$ minute post-intubation ( $\mathrm{P}-$ Value $<0.05)$.

Table (6) : changes in mean diastolic blood pressure

\begin{tabular}{|c|c|c|c|c|c|c|c|}
\hline \multicolumn{2}{|c|}{ DBP } & Group & $\mathrm{N}$ & Mean & $\mathrm{SD}$ & $\begin{array}{l}\text { Std. } \\
\text { Error }\end{array}$ & P-Value \\
\hline \multirow{2}{*}{\multicolumn{2}{|c|}{ Basal }} & NL & 40 & 73.96 & 9.45 & 1.49 & \multirow{2}{*}{0.6597} \\
\hline & & $\mathrm{SL}$ & 40 & 74.86 & 8.75 & 1.38 & \\
\hline \multirow{8}{*}{ 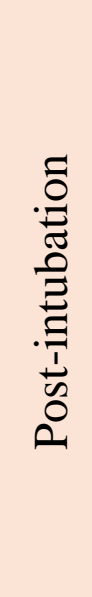 } & \multirow{2}{*}{$1 \mathrm{~min}$} & NL & 40 & 77.08 & 9.12 & 1.44 & \multirow{2}{*}{0.0417} \\
\hline & & $\overline{\mathrm{SL}}$ & 40 & 81.16 & 8.49 & 1.34 & \\
\hline & \multirow{2}{*}{$3 \mathrm{~min}$} & NL & 40 & 76.84 & 8.32 & 1.31 & \multirow{2}{*}{0.0353} \\
\hline & & SL & 40 & 80.88 & 8.55 & 1.35 & \\
\hline & \multirow{2}{*}{$6 \mathrm{~min}$} & NL & 40 & 76.31 & 9.37 & 1.48 & \multirow{2}{*}{0.0413} \\
\hline & & SL & 40 & 80.43 & 8.36 & 1.32 & \\
\hline & \multirow{2}{*}{$9 \mathrm{~min}$} & NL & 40 & 74.86 & 8.95 & 1.41 & \multirow{2}{*}{0.2484} \\
\hline & & SL & 40 & 77.15 & 8.66 & 1.36 & \\
\hline
\end{tabular}




\begin{tabular}{|l|l|l|l|l|l|l|l|}
\hline \multirow{2}{*}{$12 \mathrm{~min}$} & $\mathrm{NL}$ & 40 & 74.16 & 7.98 & 1.26 & \multirow{2}{*}{0.1237} \\
\cline { 3 - 8 } & & $\mathrm{SL}$ & 40 & 76.97 & 8.17 & 1.29 & \\
\hline
\end{tabular}

In group NL (nebulized lidocaine) the basal value of DBP was $(73.96 \pm 9.45) \mathrm{mmHg}, 1$ minute following intubation, the SBP increased to $(77.08 \pm 9.12) \mathrm{mmHg}$. This elevated pressure started coming down by 3 minutes $(76.84 \pm 8.32) \mathrm{mmHg}$. By 6, 9 and 12 minutes it was (76.31 \pm 9.37$)$, (74.86 \pm 8.95$)$, and (74.16 \pm 7.98$) \mathrm{mmHg}$ respectively.

In group SL (sprayed lidocaine) the basal value of SBP was (74.86 \pm 8.75$)$ $\mathrm{mmHg}, 1$ minute following intubation, the DBP increased to $(81.16 \pm 8.49)$ mmHg. This elevated pressure started coming down by 3 minutes $(80.88 \pm 8.55) \mathrm{mmHg}$. By 6,9 and 12 minutes it was $(80.43 \pm 8.36)$, (77.15 \pm 8.66$)$, and $(76.97 \pm 8.17) \mathrm{mmHg}$ respectively. There was statistical significance between two groups in the $1 \mathrm{st}, 3^{\text {rd, }}$ and 6 th minute postintubation (P-Value $<0.05)$.

Table (7): changes in the mean of mean arterial pressure

\begin{tabular}{|c|c|c|c|c|c|c|c|}
\hline \multicolumn{2}{|c|}{ MAP } & Group & $\mathrm{N}$ & Mean & SD & $\begin{array}{l}\text { Std. } \\
\text { Error }\end{array}$ & P-Value \\
\hline \multirow{2}{*}{\multicolumn{2}{|c|}{ Basal }} & NL & 40 & 89.44 & 10.15 & 1.60 & \multirow{2}{*}{0.5812} \\
\hline & & SL & 40 & 90.64 & 9.20 & 1.45 & \\
\hline \multirow{10}{*}{ 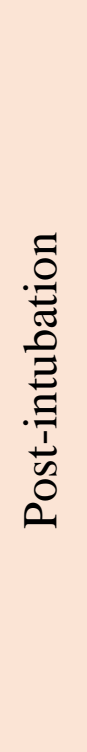 } & \multirow{2}{*}{$1 \mathrm{~min}$} & NL & 40 & 93.09 & 10.49 & 1.65 & \multirow{2}{*}{0.0275} \\
\hline & & SL & 40 & 98.39 & 10.61 & 1.67 & \\
\hline & \multirow{2}{*}{$3 \min$} & NL & 40 & 93.36 & 10.10 & 1.59 & \multirow{2}{*}{0.0299} \\
\hline & & SL & 40 & 98.52 & 10.75 & 1.69 & \\
\hline & \multirow{2}{*}{$6 \mathrm{~min}$} & NL & 40 & 92.41 & 10.53 & 1.66 & \multirow{2}{*}{0.0504} \\
\hline & & SL & 40 & 97.02 & 10.22 & 1.61 & \\
\hline & \multirow{2}{*}{$9 \min$} & NL & 40 & 90.55 & 9.81 & 1.54 & \multirow{2}{*}{0.2254} \\
\hline & & SL & 40 & 93.24 & 9.88 & 1.55 & \\
\hline & \multirow{2}{*}{$12 \mathrm{~min}$} & NL & 40 & 89.06 & 8.99 & 1.42 & \multirow{2}{*}{0.1416} \\
\hline & & SL & 40 & 92.09 & 9.26 & 1.46 & \\
\hline
\end{tabular}


In group NL (nebulized lidocaine) the basal value of MAP was (89.44 \pm 10.15$) \mathrm{mm} \mathrm{Hg}, 1$ minute following intubation, the MAP increased to $(93.09 \pm 10.49) \mathrm{mmHg}$. This elevated pressure started coming down by 6 minutes $(92.41 \pm 10.53) \mathrm{mmHg}$. By 3, 9 and 12 minutes it was $(93.36 \pm 10.1)$, (90.55 \pm 9.81$)$, and $(89.06 \pm 8.99) \mathrm{mmHg}$ respectively. In group SL (sprayed lidocaine) the basal value of MAP was $(90.64 \pm 9.20) \mathrm{mmHg}, 1$ minute following intubation, the MAP increased to $(98.39 \pm 10.61) \mathrm{mm} \mathrm{Hg}$.

\section{Discussion}

King et al., ${ }^{[32]}$ in 1951 first described sympathetic hemodynamic response to laryngoscopy and endotracheal intubation. Direct laryngoscopy exerting a pressure over the base of the tongue by the laryngoscope blade stimulates proprioceptors, resulting in a significant proportionate increase in catecholamine and hemodynamic parameters. Orotracheal intubation consists of two phases: Direct laryngoscopy and passing of endotracheal tube through the vocal cords and trachea ${ }^{[33]}$, It has been seen in various studies that increase in HR occurs during endotracheal intubation whereas the greatest increase in BP occurs during laryngoscopy. ${ }^{[34]}$

Lidocaine was administered by different routes (intravenous, airway topicalization, endotracheal, as well as airway nerve block) with different techniques and concentrations and was compared with each other and with other drugs for blunting of hemodynamic response to laryngoscopy and tracheal intubation. Each route has its own merits and demerits.

Nebulized lidocaine received great attention from researchers in several studies, most of which compare nebulized lidocaine with intravenous one.

The average age in the study groups was 30.34 years old, 30 male and 50 female, the average weight was $66.42 \mathrm{~kg}$ and there were no significant differences regarding baseline characteristics between the study groups. 
According to the findings of this study, there is a significant difference in heart rate, systolic, diastolic, and mean arterial pressure between both groups. In NL (nebulizes lidocaine) group the basal heart rate was 71.06) bpm, 1 minute after intubation it was (74.96) bpm. There was a difference of approximately (3.9) bpm (5.48\%) while in SL (sprayed lidocaine) group it was (69.92) bpm increased by (8.1) bpm (11.58\%) 1 minute after intubation. It was significant difference between groups at $1 \mathrm{st}$, 3rd, and 6th minute after intubation (P-value > 0.05).

Regarding blood pressure observation, there was significant difference in SBP, DBP, and MAP at (1st, 2nd), (1st, 2nd, 6th), and (1st, 2nd) min. respectively.The changes in SBP, DBP and MAP following 1minute of laryngoscopy and intubation in the pre-treatment group with lignocaine nebulization to be $4.71 \mathrm{mmHg}, 3.12 \mathrm{mmHg}$ and $3.65 \mathrm{mmHg}$ respectively. Bahaman Venus et al. ${ }^{[40]}$ noticed increase in the SBP, DBP, and MAP to be $2.7 \mathrm{mmHg}, 4 \mathrm{mmHg}$, and $3.4 \mathrm{mmHg}$ respectively.

\section{Conclusion:}

Based on results of present study it may be concluded that the hemodynamic instability was lesser with nebulized lidocaine $(1 \mathrm{ml}$ of $10 \%)$ as compared to sprayed lidocaine ( $1 \mathrm{ml}$ of $10 \%)$. The effect was on heart rate, systolic, diastolic and mean arterial blood pressure. Use of nebulized lidocaine is simple, safe, effective, applicable and better patient acceptance. It is also convenient nowadays due to availability of nebulizer in all centers.

\section{References}

1. Shribman AJ, Smith G, Achola KJ: Cardiovascular and catecholamine responses to laryngoscopy with or without tracheal intubation. British Journal of Anesthesia 1987; 59:295 
2. Burstein CL, Lo Pinto FJ and Newman W. Electrocardiographic studies during endotracheal intubation 1, effects during usual routine techniques. Anesthesiology. 1950; 11:224.

3. Robert K. Stoelting. Blood pressure and heart rate changes during shortduration laryngoscopy for tracheal intubation. Influence of viscous or intravenous lidocaine. Anesthesia Analgesia. 1978; 57: 197-199.

4. Prys-Roberts, Greene LT, Meloche R and Foex P. Studies of anesthesia in relation to hypertension-II. Hemodynamic consequences of induction and endotracheal intubation. British Journal of Anesthesia. 1971; 43: 541-547.

5. Forbes AM and Dally FG. Acute hypertension during induction of anesthesia and endotracheal intubation in normotensive man. British Journal of Anesthesia. 1970; 42: 618-622.

6. Fox EJ, Sklar GS, Hill CH, Villanueva R, King BD: Complications related to the pressor response to endotracheal intubation. Anesthesiology 1977; 47:524-525.

7. Dalton B and Guiney $\mathrm{T}$ et al. Myocardial ischaemia from tachycardia and hypertension in coronary heart disease - Patient's undergoing anesthesia. Ann. Mtg. American Society of Anaesthesiologists, Boston. 1972; pp. 201202.

8. Donegan MF and Bedford RF. Intravenously administered lidocaine prevents intracranial hypertension during endotracheal suctioning. Anesthesiology, 1980; 52:516-518.

9. Nair GC, Hariwar Singh and Preetam Singh. Vital signs and during intubation. Indian Journal of Anesthesia. 1965 Feb; 40-57. 
10. Bedford RF and Lt Marshal K. Cardiovascular responses to endotracheal Intubation during four anaesthetic techniques. Acta Anaesthesiologica Scandinavia. 1984; 28: 563-566.

11. Braude N, Clements EA, Hodges UM, and Andrews BP. The pressor response and laryngeal mask insertion. A comparison with tracheal intubation. Anesthesia 1989; 44:551.

12. Wood ML, Forrest ET: The haemodynamic response to the insertion of the laryngeal mask airway: A comparison with laryngoscopy and tracheal intubation. Acta Anaesthesiol Scand 1994; 38: 510.

13. Chen C: Fentanyl dosage for suppression of circulatory response to laryngoscopy and endotracheal intubation. Anesthesiol Rev 1986; 13:37.

14. Devault M, Greifenstein FE and Harris JR. LC. Circulatory responses to endotracheal intubation in light general anesthesia; the effect of atropine and phentolamine. Anesthesiology. 1960; 21: 360-362.

15. Prys-Roberts C, Foex P, Biro GP and Roberts JG. Studies of anesthesia in relation to hypertension - V: Adrenergic beta-receptor blockade. British Journal of Anesthesia. 1973; 45: 671-680.

16. Mikawa K, Nishina K, Maekawa N, Obara H: Comparison of nicardipine, diltiazem and verapamil for controlling the cardiovascular responses to tracheal intubation. British Journal of Anesthesia 1996; 76:221.

17. Gallagher JD, Moore RA, Jose AB, et al: Prophylactic nitroglycerin infusions during coronary artery bypass surgery. Anesthesiology 1986; 64:785.

18. Mikawa K, Nishina K, Maekawa $\mathrm{N}$, et al: Attenuation of the catecholamine response to tracheal intubation with oral clonidine in children. Canadian Society Anesthesia Journal. 1995; 42:869. 
19. Aho M, Lehtinen AM, Erkola O, et al: The effects of intravenously administered dexmedetomidine on perioperative hemodynamiccs and isoflurane requirements in patients undergoing abdominal hysterectomy. Anesthesiology 1991; 74:997 - 1002.

20. Stoelting RK: Circulatory response to laryngoscopy and tracheal intubation with or without prior oropharyngeal viscous lidocaine. Anesth Analg 1977; 56: 618

21. Abou-Madi M, Keszler H, and Yacoub O. A method for prevention of cardiovascular reactions to laryngoscopy and intubation. Canadian Society Anesthesia Journal. May 1975; 22: 316.

22. Williams KA, Barker GL, Harwood RJ, Woodall NM. Combined nebulization and spray-as-you-go topical local anesthesia of the airway. British Journal of Anesthesia. 2005; 95:549-553.

23. Abou-Madi M, Keszler H, and Yacoub JM. Cardiovascular reactions to laryngoscopy and tracheal intubation following small and large intravenous dose of lidocaine. Canadian Society Anesthesia Journal. 1977; 24(1):12-18.

24. Tam S, Chung F, and Michael Campbell M. Intravenous lidocaine: Optimal time for injection before tracheal intubation. Anesth Analg.1987; 66: 1036-1038.

25. Sant'Ambrogio G. Nervous receptors of the tracheobronchial tree.

Annu Rev Physiol. 1987;49:611-627.

26. Hassan HG, el-Sharkawy TY, Renck H, et al. Hemodynamic and catecholamine responses to laryngoscopy with vs. without endotracheal intubation. Acta Anaesthesiol Scand. 1991;35:442-447. 
27. Kinney MAO, Warner ME, vanHeerden JA, et al. Perianesthetic risks and outcomes of pheochromocytoma and paraganglioma resection. Anesth Analg. 2000;91:1118-1123.

28. Mi WD, Sakai $\mathrm{T}$, Takahashi $\mathrm{S}$, et al. Haemodynamic and electroencephalograph responses to intubation during induction with propofol or propofol/fentanyl. Can J Anaesth. 1998; 45:19-22.

29. Kamal Maheshwari, Mohamed A. Naguib. Pharmacology and Physiology in Anesthetic Practice. 5ed. Philadelphia: Wolters Kluwer Health; 2015. Page:282

30. Rithesh D¥Cunha, Shannon Fernandes, Elory Saldanha, A STUDY OF THE EFFECT OF PRETREATMENT WITH LIDOCAINE AND DICLOFENAC IN REDUCING SUCCINYLCHOLINE INDUCED MYALGIA, INDIA JOURNAL OF APPLIED RESEARCH : Volume 7/ Issue 4/ April-2017

31. Collins VJ. Local Anesthetics. In: Principles of Anesthesiology General and Regional Anesthesia. 3 ed. Philadelphia: Lea and Febiger; 1993.

32. King BD, Harris LC, Jr, Greifenstein FE, Elder JD, Jr, Dripps RD. Reflex circulatory responses to direct laryngoscopy and tracheal intubation performed during general anesthesia. Anesthesiology. 1951;12:556-66

33. Singh S, Smith JE. Cardiovascular changes after the three stages of nasotracheal intubation. Br J Anaesth 2003;91:667-71

34. Hassan HG, el-Sharkawy TY, Renck H, Mansour G, Fouda A. Hemodynamic and catecholamine responses to laryngoscopy with vs. Without endotracheal intubation. Acta Anaesthesiol Scand 1991;35:442-7. 